\title{
Sexual function in patients with Parkinson's disease and their partners
}

\author{
R G Brown, M Jahanshahi, N Quinn, C D Marsden
}

\begin{abstract}
Sexual function in patients with Parkinson's disease has received virtually no attention. There are many reasons (physical, psychological and social), why such patients might experience problems within their sexual relationships. A group of patients and their partners completed a series of self-report measures, aimed at assessing sexual function and a range of factors which might be associated with any difficulties. The results revealed a high level of dysfunction, not just in the patients but also in their partners. Most effected were the couples in which the patient was male. A range of problems were reported by both patients and their partners. These were, in turn, associated with a range of variables relating to the disease, psychological and social factors. No simple causal model was suggested, and a multimodal therapeutic approach might be expected to have most benefit.
\end{abstract}

Sexual dysfunction in individuals with a physical illness or disability is only slowly starting to receive attention. ${ }^{1}$ The focus has been on a limited number of conditions such as multiple sclerosis, spinal cord injury, diabetes, stroke, myocardial dysfunction, and cancer. Parkinson's disease has received scant attention. Lipe $e t a l^{2}$ reported a study in which the sexual function of a group of male Parkinson's disease patients were compared with a group with arthritis. Sexual problems were found to increase with both disease severity and depression in both groups. Except for more problems with arousal in the Parkinson's disease groups, the two groups were similar in all measured aspects of sexual functioning. The only other studies have been limited to reports of hypersexuality resulting from levodopa treatment. ${ }^{34}$

The general lack of professional interest in the subject of sexual function in Parkinson's disease may relate to two main assumptions, neither of which are warranted. First, Parkinson's disease is not generally assumed to be associated with physiological dysfunction or neuronal damage that would interfere with the sexual response. Autonomic dysfunction affecting the urinogenital system is, however, found in some patients with idiopathic Parkinson's disease. Further, in some patients with Parkinsonism, such autonomic dysfunction may be a major problem as a symptom of more general multiple system atrophy. Second, there may be an implicit assumption that patients with Parkinson's disease, being generally middle-aged or elderly, are not interested or have a diminishing interest in sex. While the frequency of sexual intercourse may diminish with age, this does not mean that sexuality plays no role in the lives of the elderly. This assumption also ignores the significant proportion of cases with early onset Parkinson's disease who develop the disease in early or midadulthood when reduced sexual activity is not the norm.

While autonomic nervous system involvement may be a possible cause of primary sexual dysfunction in some patients with Parkinson's disease, many other factors may lead or contribute to secondary sexual dysfunction, either in the patient, their partner or both. The motor symptoms of Parkinson's disease may make the act of sexual intercourse difficult. Fatigue may also play a role. Anti-Parkinsonian medication may have some effect on both libido and the sexual response. The hypersexuality reported in some patients may be a problem where the desire for an increase in the frequency of sexual intercourse is not shared by both partners. Diminishing physical capacity may necessitate the patient taking on a more passive role. In addition, because of drug regimes, motor function for many patients is at its best in the morning, and worst at night. A shift in the pattern of sexual activity may therefore be desirable to take advantage of the optimum motor status of the patient. Difficulties may develop in couples who do not try, or are unwilling to make, such adaptive changes to their previous patterns of sexual behaviour, either in its timing, or in the roles played by individual partners. Further, if the patient's movement disorder is disruptive at night, the couple may take to sleeping in separate beds or even separate rooms, thus decreasing the opportunity for spontaneous sexual contact.

Depression and anxiety are common in patients with Parkinson's disease. ${ }^{56}$ Increased psychological morbidity may also be found in those living with and caring for the patients. Anxiety and depression, whether in the patient or partner, may affect libido and sexual performance. Parkinson's disease may place considerable stress on the sufferer and his/her partner. The patient may have to receive more care than he/she has been used to or is willing to accept, possibly leading to reduced self-esteem. The extra demands on the time and energy of the partner may require significant adjustments to work commitments and leisure time. 
Where the patient is the main breadwinner, financial difficulties may develop or there may be anxiety about the prospect of premature retirement. The partner may have to become the main financial provider, with the patient taking on unaccustomed roles at home. Such dramatic role changes may lead to considerable disruption within a relationship. The influence of such stress on the patient's and his/her partner's sex lives will depend upon their ability to adapt to such changes.

The impact of these factors on the couple's sex life and marriage will depend, partly, on their ability to discuss the problems. Interpersonal communication, however, may be compromised by Parkinson's disease, with some sufferers having a reduced range of verbal and nonverbal emotional expression. Further stress may be caused where a partner misinterprets the patient's communications as reflecting boredom or disinterest. Against this complex background, the following questions were addressed.

1 How common is sexual dysfunction in patients with Parkinsonism and/or their partners?

Accurate epidemiological data on sexual dysfunction is notoriously difficult to obtain, and any estimate of prevalence will be subject to a wide margin of error or possible bias. Even an inexact estimate, however, will allow some comparison to be made between Parkinsonism, other disabling illnesses, and healthy individuals where similar response biases are likely to operate.

2 What is the nature of the sexual difficulties experienced by patients with Parkinsonism and/or their partners?

Are the problems the same as those encountered in the general population, or are certain classes of dysfunction over-represented? The pattern of dysfunction in the Parkinsonian population may give some clues as to the mechanisms underlying the problems.

3 What are the relationships between sexual dysfunction, psychological morbidity, psychosocial stress, physical disability and physiological (autonomic) dysfunction?

Is it possible to build a model of sexual dysfunction in couples where one partner has Parkinsonism, based on these multiple factors?

Table 1 Characteristics of the patients, and their medication (number and percentage of patients)

\begin{tabular}{lccc}
\hline & $\begin{array}{l}\text { Male }(n=23) \\
\text { mean }(S D)\end{array}$ & $\begin{array}{l}\text { Female }(n=11) \\
\text { mean }(S D)\end{array}$ & $\begin{array}{l}\text { Total sample } \\
(n=34) \\
\text { mean }(S D)\end{array}$ \\
\hline Age & $51 \cdot 9(8 \cdot 9)$ & $44 \cdot 7(7 \cdot 2)$ & $49 \cdot 6(8 \cdot 9)$ \\
Age of onset of Parkinsonism & $41 \cdot 2(8 \cdot 9)$ & $31 \cdot 8(8 \cdot 7)$ & $38 \cdot 8(9 \cdot 8)$ \\
Duration of Parkinsonism & $10 \cdot 0(4 \cdot 3)$ & $12 \cdot 9(5 \cdot 9)$ & $11 \cdot 0(4 \cdot 9)$ \\
Disability (self-rated ADL) & $52 \cdot 2(21 \cdot 9)$ & $54 \cdot 3(28 \cdot 2)$ & $52 \cdot 9(23 \cdot 8)$ \\
Mean levodopa dose (mg/day) & $777(447)$ & $645(441)$ & $734(447)$ \\
Medication & & & $\mathrm{N}(\%)$ \\
Levodopa & & $33(97)$ \\
Bromocriptine & & $10(29)$ \\
Selegiline & & & $16(47)$ \\
Amantadine & & $2(6)$ \\
Anticholinergics & & $9(26)$ \\
Benzodiazapines & & $7(21)$ \\
Antidepressants & & $3(9)$ \\
Analgesics & & $2(6)$ \\
Antihypertensives & & $4(12)$ \\
Lithium & & $1(3)$ \\
\hline
\end{tabular}

\#In calculating mean levodopa dose, $10 \mathrm{mg}$ Bromocriptine was taken as equivalent to $100 \mathrm{mg}$ of levodopa.
Such a model may suggest therapeutic strategies to help treat or prevent sexual dysfunction in patients and their partners.

\section{Method}

1 The sample

The sample was drawn from couples attending a weekend residential meeting for Parkinsonian patients and their partners or carers, organised by the Parkinson's Disease Society (United Kingdom). The meeting was aimed particularly at younger patients. They were believed to have idiopathic Parkinson's disease, although the possibility that a small proportion may have had other Parkinsonian syndromes cannot be ruled out. However, none had severe autonomic dysfunction (see below). Forty four couples were present and all were invited to participate in the present study. Thirty eight spouses $\left(86^{\circ}\right.$ ) completed questionnaires, as did 34 patients $(77 \%)$. Completed questionnaires from both partners were received from 33 couples $(75 \%)$.

Of the patient sample, 23 were male and 11 female. The spouse group showed the complementary pattern, with 27 female and 11 male. The couples had been married, on average, for 21 years (SD 7.9) with a minimum of three years. Details of the patients are shown in table 1 . Of the male patients, $39 \%$ were in employment, either full or part-time, while $57^{\circ}$ o had retired on medical grounds. Ninety one per cent of the male spouses were still working. The remainder were either unemployed or retired because of age. Of the female patients, only $18 \%$ were in outside employment (compared to $48 \%$ of female spouses). Thirty six per cent of the female patients had retired on medical grounds. Socioeconomic status was assessed using the criteria set by the Registrar General. ${ }^{7}$ In class I there were $13.9 \%, 44.4 \%$ in II, $38.9 \%$ in III and $2.8 \%$ in IV.

\section{The assessment measures}

a Illness related information

Information about age of onset of the Parkinsonism was obtained from both patient and partner. Where there was disagreement, the average was taken. Patients gave information about current medication. Physical disability was assessed using the ADL scale described previously. ${ }^{6}$ Both the patient and their partner rated the patient's disability independently. Agreement between the patient's self-rating and the relative's rating of the patient was generally high. ${ }^{8}$

\section{b Sexual function}

This was assessed by the Gollombok Rust Inventory of Sexual Satisfaction (GRISS). ${ }^{9}$ This is a 28 item questionnaire with a male and female form. Responses are summed to give a total raw score (range 28-140). In addition, for each sex, six subscale scores are derived (see table 2). The total score and subscale scores are transformed using a standard nine point scale, with high scores indicating greater problems. Scores of five or more are considered to 
Table 2 Sexual Satisfaction (GRISS) and Marital State (GRIMS)

\begin{tabular}{|c|c|c|c|c|c|c|c|c|}
\hline & \multicolumn{2}{|c|}{ Male patients $(n=20)$} & \multicolumn{2}{|c|}{ Female spouses $(n=26)$} & \multicolumn{2}{|c|}{ Female patients $(n=11)$} & \multicolumn{2}{|c|}{ Male spouses $(n=11)$} \\
\hline & Mean $(S D)$ & $\begin{array}{l}{ }_{o}^{o} \text { above } \\
\text { cut-off }\end{array}$ & Mean (SD) & $\begin{array}{l}\% \text { above } \\
\text { cut-off }\end{array}$ & Mean $(S D)$ & $\begin{array}{l}\% \text { above } \\
\text { cut-off }\end{array}$ & Mean (SD) & $\begin{array}{l}\% \text { above } \\
\text { cut-off }\end{array}$ \\
\hline \multicolumn{9}{|c|}{ Sexual Satisfaction (GRISS) } \\
\hline Total & $5 \cdot 2(1 \cdot 7)$ & $65^{\circ} \mathrm{o}$ & $5 \cdot 0(2 \cdot 3)$ & $52 \%$ & $3 \cdot 6(2 \cdot 2)$ & $36 \%$ & $2 \cdot 0(1 \cdot 2)$ & $0 \%$ \\
\hline Infrequency & $6 \cdot 9(2 \cdot 2)$ & $80^{\circ}$ o & $6 \cdot 8(2 \cdot 2)$ & $80 \%$ & $5 \cdot 7(2 \cdot 2)$ & $82 \%$ & $4 \cdot 6(1 \cdot 8)$ & $45 \%$ \\
\hline Non-communication & $4.7(1.9)$ & $45^{\circ}$ & $5 \cdot 8(2 \cdot 4)$ & $72 \%$ & $5 \cdot 4(1.6)$ & $64 \%$ & $3.0(1 \cdot 3)$ & $18 \%$ \\
\hline $\begin{array}{l}\text { Dissatisfaction } \\
\text { Avoidance }\end{array}$ & $4.8(2.5)$ & $50^{\circ} \circ$ & $4 \cdot 4(2 \cdot 0)$ & $44 \%$ & $3.3(2.0)$ & $18 \%$ & $2 \cdot 0(1 \cdot 1)$ & $0 \%$ \\
\hline Avoidance & $2.8(1.9)$ & $25^{\circ} \%$ & $5 \cdot 6(2 \cdot 3)$ & $76 \%$ & $4.5(2 \cdot 0)$ & $55 \%$ & $1.6(1.0)$ & $0 \%$ \\
\hline Non-sensuality & $2 \cdot 5(1 \cdot 6)$ & $20^{\circ} \%$ & $6 \cdot 0(2 \cdot 6)$ & $72 \%$ & $3 \cdot 5(2 \cdot 3)$ & $27 \%$ & $1.6(1.0)$ & $0 \%$ \\
\hline Premature ejaculation & $6 \cdot 0(1 \cdot 6)$ & $65^{\circ} \circ$ & - & - & - & - & $3.4(1 \cdot 0)$ & $9 \%$ \\
\hline Impotence & $4.5(1.7)$ & $60^{\circ}{ }_{0}$ & - & - & - & - & $2 \cdot 8(1 \cdot 8)$ & $18 \%$ \\
\hline Vaginismus & - & - & $3.4(2 \cdot 6)$ & $40 \%$ & $3 \cdot 2(2 \cdot 4)$ & $27 \%$ & - & - \\
\hline $\begin{array}{l}\text { Anorgasmia } \\
\text { Marital State (GRIMS) }\end{array}$ & - & - & $4 \cdot 6(2 \cdot 3)$ & $52 \%$ & $4 \cdot 3(2 \cdot 0)$ & $36 \%$ & - & - \\
\hline Total & $4 \cdot 7(2 \cdot 5)$ & $42^{\circ}{ }_{0}$ & $5 \cdot 4(2 \cdot 6)$ & $62 \%$ & $3 \cdot 9(2 \cdot 2)$ & $9 \%$ & $2 \cdot 8(1.8)$ & $9 \%$ \\
\hline
\end{tabular}

indicate sexual dysfunction. In addition, participants were asked two questions about their sexual relationship. First, "Overall, how satisfactory to you is your sexual relationship with your current partner?". Subjects answered on a six point scale from "extremely satisfied" to "extremely unsatisfied". Second, "Do you consider that you and your partner have any problem with sex?", answered on a five point scale from "no problem" to "severe problem". Finally, participants were given the opportunity to describe any sexual problems which they perceived.

\section{c Marital function}

This was assessed using the Golombok Rust Inventory of Marital State (GRIMS). ${ }^{10}$ This 28 item questionnaire contains a series of positive and negative statements about marriage in general and the respondent's marriage in particular. Subjects indicate the degree to which they agreed or disagreed with each statement. A total score is computed (range $0-84$ ), with a high score indicating likely marital problems. As with the GRISS, raw scores are converted to standard scores (range 1-9), with a cut-off of five.

\section{d Psychological function}

Depression and anxiety in both patients and spouses were assessed using the Beck Depression Inventory (BDI), ${ }^{11}$ and the trait form of the Spielberger Stait-Trait Anxiety Inventory (STAI). ${ }^{12}$ In addition, patients completed the Acceptance of Illness Scale (AOI), ${ }^{13}$ designed to assess acceptance of the sick-role in the context of a long-term illness. Subjects indicate on a five point scale, the degree to which they agree or disagree with each statement. A high score indicates poor acceptance of illness. Spouses completed an adapted version of the Care-giver Strain Index (CSI), ${ }^{14}$ designed to assess the strain brought about by caring for a disabled individual. Subjects indicate whether or not they agreed or disagreed with each of 13 statements. A high score (range 1-13) indicates high levels of strain.

\section{e Autonomic function}

Patients completed a questionnaire designed to assess autonomic function. Questions were asked about urination and incontinence, childbirth (females), prostatectomy and erectile function (males), bowel function, blood pres- sure, faintness and dizziness, and sweating. Three neurologists, blind to the other results from the study, independently rated the likely presence of autonomic dysfunction on a four point scale $(0=$ "definitely none", $1=$ "possible", 2 = "probable", 3 = "definite"). In the event, none of the patients received a rating of three from any of the raters, and the difference between "possible" and "probable" was judged to be too subjective. Patients thus received a rating of 0 (definitely no dysfunction) or one (possible or probable dysfunction). Where there was disagreement, the majority decision was taken from the three ratings.

\section{Statistical analysis}

Between groups analysis was performed using $t$ test for independent samples. Frequency data were analysed using Chi-square and the Pearson correlation coefficient was used for testing associations. Two-tailed tests were used throughout.

\section{Results}

1 Age and health

The male patients were significantly older than the female patients $(p<0.05)$, and had a later age of onset ( $p<0.05)$, although duration of illness did not differ. Degree of disability for male and female patients, as measured by the ADL scale, did not differ, either for the ratings made by their spouses, or by the patients themselves. The patients' self-rating of their disability was highly correlated with the ratings made by their spouses $(\mathrm{r}=0.90, \mathrm{p}<0.05)$. No difference in age was found between the male and female spouse groups, between the male patients and male spouses, or between the female patients and female spouses. Significant illness other than Parkinsonism (for example, arthritis, hypertension, diabetes) was more common in the male patients, with $34.8 \%$ reporting at least one condition. In contrast only $18.2 \%$ of the female patients reported a medical condition other than their Parkinsonism. The difference, however, was not significant. Of the spouses, $9 \%$ of the males and $18 \%$ of the females had a significant illness. The difference was not significant.

\section{Sexual relationship}

a Overall satisfaction with sexual relationship and perception of problem 
In response to the question on satisfaction ("Overall, how satisfactory to you is your sexual relationship with your partner?") there were clear differences between the four groups. Dividing the responses into "satisfied" (slightly to extremely) and "dissatisfied" (slightly to extremely) reveals that, in the patients, $59 \%$ of the males were dissatisfied compared to $36 \%$ of the females. Of the spouses, only $9 \%$ of the males were dissatisfied compared to $58 \%$ of females. Thus, dissatisfaction was greatest, in both partners, in couples where the patient was male. Essentially the same pattern is found with the second question ("Do you consider that you and your partner currently have any problem with sex?, perception of a sexual problem"). Moderate to severe problems are perceived by $68 \%$ of male patients and $64^{\circ}{ }_{0}$ of female spouses, as against $36^{\circ}$ o of female patients and $27 \%$ of male spouses. On the nature of the problem, the descriptions yielded little in the way of analysable data, and these will be briefly mentioned in the discussion.

\section{b Sexual function-GRISS}

Table 2 presents the scaled score data obtained from the GRISS questionnaires. The highest total scores were obtained by the male patients and female spouses, with a large proportion of cases in these two groups $(65 \%$ and $52 \%$ respectively) scoring above the cut-off, indicating the likely presence of sexual dysfunction. In the couples with a female patient and a male spouse, total scores were generally lower. However, over one third of female patients gave scores indicating possible sexual problems while none of their spouses scored above the cut-off. Within couples, there was a significant association between the total score of the patient and that of the spouse $(r=0.64$, $\mathrm{p}<0.001$ ).

Of the individual GRISS subscales, infrequency of sexual behaviour was high in all cases except the male spouses. In general, male partners had the lowest scores on all subscales, with the means in all cases, except infrequency, being within the normal range. The female patients, in contrast, showed moderately high mean scores on several of the subscales: noncommunication, avoidance and anorgasmia, while a small number indicated problems with non-sensuality and vaginismus. This same group, however, reported relatively low levels of dissatisfaction.

The male patients scored higher than the male spouses on all subscales, although the differences were slight for avoidance and nonsensuality. A substantial proportion of the male patients showed possible dysfunction in the areas of non-communication, dissatisfaction, premature ejaculation and impotence. In the female spouses, a consistent picture of sexual dysfunction is seen across all subscales, with scores suggesting problems in $40 \%$ or more in each case. Particularly high were the levels of non-communication, avoidance and non-sensuality.

\section{Marital relationship-GRIMS}

Table 2 also shows the scaled total scores on the GRIMS for the four groups. The greatest marital dissatisfaction was shown by the male patients and their partners. This is particularly clear when considering the percentage scoring above the scaled-score cut-off of five, indicating likely marital dissatisfaction. In contrast, the large majority of female patients and their partners had scores within the normal range. The patient's and spouse's ratings were significantly associated $(r=0.60, p<0.001)$.

\section{Psychological factors}

Table 3 shows the mean scores of the four groups on the various indices of psychological function. The highest BDI scores were obtained by the two patient groups. The mean BDI scores of male and female patients did not differ significantly, with $36 \%$ of the female patients scoring above the cut-off score of $17,{ }^{15}$ compared to $29^{\circ}{ }_{0}$ of the males. In the spouses, females scored significantly higher than males $(\mathrm{p}<0.01)$. While none of the male spouses scored over $17,15^{\circ}$ of the females did so.

As with depression, trait anxiety, as measured by the STAI, did not distinguish male and female patients, but again female spouses scored higher than male spouses $(p<0.01)$. Mean acceptance of illness, as measured by the AOI scale, was identical in male and female patients. Strain in the spouse, as measured by the CSI, did not differ between males and females.

\section{Autonomic function in the patients}

Fifteen patients $(44.1 \%)$ were rated as having "possible" or "probable" autonomic dysfunction, while 19 patients $(55.9 \%)$ showed no evidence of dysfunction. Of the male patients, $39 \%$ received a rating of possible/probable dysfunction compared to $54.5 \%$ of females. The difference, however, was not significant. The presence of possible/probable autonomic dysfunction appeared unrelated to the taking of any medication, either anti-Parkinsonian, antihypertensive, antidepressant, anxiolytic or analgesic. The patients with no evidence of autonomic dysfunction did not differ from those with possible/probable dysfunction in terms of age, or age of onset of Parkinsonism, although those without evidence of dysfunc-

Table 3 Psychological factors

\begin{tabular}{|c|c|c|c|c|}
\hline & $\begin{array}{l}\text { Male patients } \\
(n=23) \\
\text { Mean }(S D)\end{array}$ & $\begin{array}{l}\text { Female spouses } \\
(n=27) \\
\text { Mean }(S D)\end{array}$ & $\begin{array}{l}\text { Female patients } \\
(n=11) \\
\operatorname{Mean}(S D)\end{array}$ & $\begin{array}{l}\text { Male spouses } \\
(n=11) \\
\text { Mean }(S D)\end{array}$ \\
\hline $\begin{array}{l}\text { Beck Depression Inventory (BDI) } \\
\text { Spielberger Anxiety Inventory (STAI) } \\
\text { Acceptance of Illness Scale (AOI) } \\
\text { Caregiver Strain Index (CSI) }\end{array}$ & $\begin{array}{l}14 \cdot 4(8 \cdot 4) \\
46 \cdot 5(12 \cdot 6) \\
3 \cdot 1(0 \cdot 8) \\
-\end{array}$ & $\begin{array}{l}11.3(6 \cdot 8) \\
44.9(9 \cdot 7) \\
77.9(3.4)\end{array}$ & $\begin{array}{l}15 \cdot 4(7 \cdot 3) \\
46 \cdot 9(8 \cdot 0) \\
3 \cdot 1(1 \cdot 1) \\
-\end{array}$ & $\begin{array}{l}4 \cdot 7(5 \cdot 1) \\
33 \cdot 7(7 \cdot 1) \\
7 \cdot 9(3 \cdot 9)\end{array}$ \\
\hline
\end{tabular}


Table 4 Patient group (male and female combined)-intercorrelations between age, disability, duration of illness, psychological, marital and sexual factors

\begin{tabular}{|c|c|c|c|c|c|c|c|}
\hline & Duration & Patient's age & $A O I$ & $B D I$ & $S T A I$ & GRIMS & GRISS \\
\hline $\begin{array}{l}\text { Disability (spouse-rated ADL) } \\
\text { Duration of Parkinsonism } \\
\text { Patient's age } \\
\text { Acceptance of illness (AOI) } \\
\text { Depression (BDI) } \\
\text { Anxiety (STAI) } \\
\text { Marital State (GRIMS) }\end{array}$ & $0 \cdot 42^{\star}$ & $\begin{array}{l}0.05 \\
0.08\end{array}$ & $\begin{array}{l}0.52^{\star \star} \\
0.42^{\star \star} \\
-0.08\end{array}$ & $\begin{array}{c}0.25 \\
0.20 \\
-0.13 \\
0.57 \star \star \star\end{array}$ & $\begin{array}{c}0.32^{\star} \\
0.17 \\
-0.06 \\
0.64^{\star \star \star} \\
0.71^{\star \star \star}\end{array}$ & $\begin{array}{c}-0.18 \\
0.01 \\
0.07 \\
-0.08 \\
0.37 \star \\
0.26\end{array}$ & $\begin{array}{l}0 \cdot 14 \\
0.35^{\star} \\
0 \cdot 31^{\star} \\
0 \cdot 26 \\
0 \cdot 33^{\star} \\
0 \cdot 16 \\
0.31^{\star}\end{array}$ \\
\hline
\end{tabular}

tion tended to be less disabled as measured by the ADL scale ( $p=0 \cdot 07)$.

\section{Relationships between variables}

Table 4 shows the correlations for the patient group, for a set of variables relating to their Parkinson's disease, and their psychological, sexual and marital function. The patient's age was significantly associated with his or her own total transformed GRISS score but not with the other indices of psychological and marital function. The patient's disability (as rated by the spouse to reduce the possibility of bias) was associated with AOI and STAI, but not with BDI, GRIMS, or GRISS scores. In contrast, duration of illness was associated with $\mathrm{AOI}$ and GRISS scores, but not with BDI, STAI or GRIMS scores. Scores on the three psychological indices, AOI, BDI and STAI, were positively and strongly associated. Only the BDI score, however, was associated with the GRIMS and GRISS scores.

All patients except one were taking a levodopa preparation, often in combination with bromocriptine. There was no significant correlation between levodopa dose and any index of sexual function from the GRISS. Insufficient numbers of patients were taking other drugs to adequately assess their possible impact on sexual function. Patients suffering from significant other illnesses did not differ from those suffering only with Parkinsonism on any of the GRISS scores. The same was true when comparing those patients with autonomic dysfunction and those without.

Table 5 gives the correlations between a set of the patient variables, and the indices of psychological, marital and sexual functioning in the spouse. While the spouse's own age was unrelated to his or her own psychological, marital or sexual function, the patient's age was significantly associated with the spouse's index of sexual dysfunction as measured by the total transformed score on the GRISS. The older the patient, the more problems the spouse reported. In contrast, the patient's age was unrelated to the spouse's scores on the CSI, STAI, BDI or GRIMS. The duration of the patient's Parkinsonism, similarly, was not significantly related to any of the index measures in the spouse. The patient's disability (as rated by the patient), however, was positively associated with the CSI, GRISS and BDI scores in the spouse, although not with STAI or GRIMS. Within the spouse group, the CSI, BDI, STAI, GRIMS and GRISS, all had moderately to highly significant associations with the exception of the CSI and STAI.

\section{Discussion}

In the introduction, three questions were posed. How common is sexual dysfuncton in patients with Parkinsonism and their partner's? What is the nature of the sexual dysfunction? How does the sexual dysfunction relate to physical and psychosocial factors?

How common is sexual dysfunction in patients with Parkinsonism and/or their partners?

Although subjective, the perception of the problem is clearly an important factor in a couple's sexual relationship. Many more male than female patients perceived a moderate to severe problem. The complementary pattern was seen in the spouse groups, suggesting a generally high frequency of problems perceived by both members in couples where the patient was male. The same picture was seen with dissatisfaction with the sexual relationship, although in all cases the proportion of individuals who were dissatisfied was less than the proportion who perceived a problem. This suggests that the presence of a sexual problem does not invariably lead to dissatisfaction, presumably through couples adopting strategies to minimise the impact of the problem on their sex life.

Normative data for perceived sexual problems and dissatisfaction are difficult to find. In a US study, Frank et al ${ }^{16}$ assessed 100 "well educated and happily married couples",

Table 5 Spouse group (male and female combined) -intercorrelations between own and patient's age, patient's disability, duration of patient's illness, psychological, marital and sexual factors.

\begin{tabular}{|c|c|c|c|c|c|}
\hline & $C S I$ & $B D I$ & $S T A I$ & GRIMS & GRISS \\
\hline $\begin{array}{l}\text { Disability (patient-rate ADL) } \\
\text { Duration of patient's Parkinsonism } \\
\text { Patient's age } \\
\text { Spouse's age } \\
\text { Strain (CSI) } \\
\text { Depression (BDI) } \\
\text { Anxiety (STAI) } \\
\text { Marital State (GRIMS) }\end{array}$ & $\begin{array}{l}0.52^{\star \star} \\
0.02 \\
-0.06 \\
-0.14\end{array}$ & $\begin{array}{l}0.40^{\star} \\
0 \cdot 21 \\
0 \cdot 16 \\
0.04 \\
0.57^{\star \star \star}\end{array}$ & $\begin{array}{l}0.18 \\
0.17 \\
0.18 \\
0.07 \\
0.25 \\
0.67^{\star \star \star}\end{array}$ & $\begin{array}{c}0 \cdot 17 \\
0.01 \\
0 \cdot 11 \\
-0 \cdot 10 \\
0 \cdot 46^{\star \star} \\
0 \cdot 71^{\star \star \star} \\
0.74^{\star \star \star}\end{array}$ & $\begin{array}{l}0 \cdot 32^{\star} \\
0 \cdot 15 \\
0 \cdot 41^{\star \star} \\
0 \cdot 01^{\star \star} \\
0 \cdot 42^{\star \star} \\
0 \cdot 60^{\star \star \star} \\
0 \cdot 53^{\star \star} \\
0 \cdot 65^{\star \star \star}\end{array}$ \\
\hline
\end{tabular}


with a mean age of $35-37$ years. Only $14 \%$ of the men and $15 \%$ of the women found their sexual relationship not very, or not at all satisfying. In a study in the United Kingdom, Osborn et $\mathrm{al}^{17}$ assessed a community sample of 436 women of varying ages. Ten per cent believed that they had a sexual problem. Judged against these figures, the levels of perceived problems and dissatisfaction in the present sample seem high, particularly for the male patient-female spouse couples. The same picture was obtained from the results of the GRISS. Sixty five per cent of the male patients and $52 \%$ of their partners could be classed as having a possible sexual dysfunction. As expected, fewer $(34 \%)$ of the female patients scored above the cut-off, while none of their spouses did so. As before, therefore, sexual difficulty appeared to be concentrated in the couples where the male is the patient.

Few data exist on sexual problems in individuals with physical disability. In what is probably the largest study to date, Stewart ${ }^{18}$ assessed a community sample of 212 disabled people, aged from 20-64 years. Most $(77 \%)$ were married. Over half ( $54 \%$ ) were currently suffering some problem which served as an obstacle to satisfaction of their sexual need. Such findings imply that sexual problems in disabled individuals and their partners, including Parkinsonism, needs to be given far greater attention.

What is the nature of the sexual difficulties experienced by patients with Parkinsonism and/or their partners?

It is necessary to consider, separately, males and females as well as patients and their partners. One problem, that of infrequency, was characteristic of all four groups. It is difficult to say whether infrequency is a problem in its own right or a result of dysfunction in other areas. Alternatively, the constraints of the disease outlined in the introduction may simply reduce the opportunities for sexual interaction. The other common problem was non-communication. This was particularly marked in the male patients and their spouses.

While levels of dysfunction were lower than in female spouses, the female patients also showed a range of sexual problems. In addition to complaints of infrequency and non-communication, a considerable proportion had orgasmic function outside the normal range. Avoidance was also indicated. It is notable that problems of non-sensuality and reduced arousal were less common than other areas of sexual dysfunction, and dissatisfaction was relatively low.

Male patients and their partners had the highest level of overall dysfunction. For the males, erectile problems were present in a significant proportion as was difficulty in ejaculatory control. In contrast, however, a relatively small proportion reported avoidance or non-sensuality. Most problems were seen in the female partners. Most striking was the high level of avoidance and non-sensuality. Dissatisfaction was also higher than in the female patients. Orgasmic function, however, was similar in the two groups, with significant proportions having difficulty.

What are the relationships between sexual dysfunction, psychological morbidity, psychosocial stress, physical disability and physiological (autonomic) dysfunction?

A number of factors were suggested which might contribute to sexual problems in patients with Parkinsonism and their partners. The aim of this section is to consider the evidence for such associations. It is important that the crosssectional nature of the study does not allow causal inferences to be made. Further, in such a complex area of interpersonal behaviour, simple models of cause and effect are unlikely to hold. For example, because of stress or physical illness, a male may suffer erectile difficulty. Performance anxiety and fear of failure may then come into play further worsening the problem and possibly maintaining it even after the initial cause has disappeared. Such a pattern of anxiety and fear of disappointment may lead to avoidance in either or both partners. Poor communication may also result in problems, including general marital disharmony leading to a worsening of both partners' sexual function. While this example illustrates the difficulty in describing simple causal relationships between sexual, physical, psychological and interpersonal factors, the exercise may be of value given our poor state of knowledge about sexual function in chronic physical illness.

The first, and most obvious question to address is whether the degree of sexual dysfunction is associated with the physical aspects of Parkinson's disease. We can consider sexual function in relation to physical disability, autonomic dysfunction and the effects of medication. Considering the level of disability, the patient's sexual dysfunction as measured by the total GRISS score, was unrelated to the level of disability, although there was an association with duration of illness. The ADL questionnaire gave only a global index of physical ability. Specific motor symptoms such as akinesia, rigidity or abnormal involuntary movements, may bear a stronger direct relationship to impaired sexual function.

Interestingly, the patient's level of disability was more strongly related to sexual function in the partner. While this may be a direct impact of the motor symptoms of the disease, it is possible that the effect was mediated via factors such as stress. Although stress in the spouse was not cited as a common factor in determining sexual problems, there was a strong relationship between the spouse's total GRISS score and the rating of care-giver strain. A further way in which the patient's physical symptoms may have an impact on the sexual relationship is if the spouse finds them physically unattractive. Symptoms such as abnormal movements, excessive sweating or salivation may all have such an effect. Three female spouses reported being "turned off" 
by such symptoms with emotions such as "anxiety" and "disgust".

As a practical obstacle, the motor symptoms of the disease were seen as the most important single factor, with a third of those who felt they had a sexual problem, attributing it directly to the motor symptoms. Interestingly, fatigue did not seem to be regarded as a problem.

Next, there is the issue of autonomic dysfunction and medication as possible causes of sexual problems. Just under half $(44 \%)$ of the patients were rated as having possible or probable autonomic dysfunction. However, this was unrelated to overall sexual function. There was no evidence that daily dosage of levodopa was related in any way to sexual function. The impact of other drugs such as antihypertensives or anticholinergics was difficult to determine because of small numbers. Hypersexuality was not assessed directly, although five female spouses reported that "excessive" demand for sex from their husbands was a problem. It is difficult to determine whether this reflected an increased libido in their husbands or a decreased desire for sex in themelves.

It would seem, therefore, that physical disability, autonomic dysfunction or adverse effects of medication, are not significant factors in determining the presence or absence of sexual dysfunction in the patients themselves, at least when considering the group as a whole. The patients' disability, however, and related strain in the spouses, were significantly associated with sexual dysfunction in the latter group.

Strain in the spouse is only one of the factors which may influence their sexual function. Depression and anxiety were also significantly associated with total GRISS score. As a general observation, sexual function was much more strongly associated with psychological factors in the spouses than in the patients. This pattern is difficult to interpret, however, as the majority of patients were male and the majority of spouses female. It is, therefore, not possible to say whether the observed pattern of associations between sexual and psychological factors was related to gender or role in the patientspouse relationship. While a range of factors seemed to be associated with sexual function in the spouse, the picture was much less clear in the patients. As already noted the level of disability did not seem important, while relatively modest associations are seen with the measures of depression, adjustment and marital state. In our present state of knowledge it is difficult to predict which patients are most likely to suffer from sexual dysfunction.

One of the strongest findings from this study was the bias in the distribution of sexual problems in couples where the patient was male. It may be that in couples where the male partner adopts the more active sexual role, the relationship may be more vulnerable to the primary and secondary effects of physical illness. Whether or not the partner goes out to work or not may affect the amount of strain on the individual and the relationship. If wives are more likely to stay at home and nurse their partners while husbands are more likely to work, then this again may contribute to the bias in the distribution of sexual difficulties.

The final question to consider is intervention. In terms of possible strategies, our results clearly indicate that the problems cannot be simply attributed to the physical symptoms of the disease. This suggests that treating the disease will not necessarily improve the sexual relationship of the patient and their partner. The corollary of this, of course, is that even in patients with marked Parkinsonian symptoms, sexual problems can be treated directly. As already mentioned, sexual dysfunction does not fit into simple models of cause and effect. Because of this, modern methods of sex therapy are typically multifaceted, and are adapted to fit the particular demands of the individual couples concerned. Physical illness and disability are just extra factors in the overall picture which can be taken into account when planning a programme of sex therapy. Patients with Parkinson's disease and their partners probably stand just as much chance to obtain benefit from such therapy as any other couple. It is important that this message reaches the patients and their partners, those responsible for the clinical management of the patient and those who offer sex therapy.

1 Wise TN. Sexual dysfunction in the medically ill. Psychosomatics 1983;24:787-805.

2 Lipe H, Longstreth WT, Bird TD, Lind M. Sexuality in Parkinson's disease. Neurology 1989;39(suppl 1):320.

3 Ballivet J, Marin A, Gisselmann A. Aspects of hypersexuality observed in parkinsonian patients treated with 1-dopa. Ann Med Psychol 1973;2:512-22.

4 Vogel HP, Schiffter R. Hypersexuality-a complication of dopaminergic therapy in Parkinson's disease. Pharmacopsychiatrica 1983;16:107-10.

5 Gotham A-M, Brown RG, Marsden CD. Depression in Parkinson's disease: a quantitative and qualitative Brown RG, MacCarthy B, Gothachiatry 1986;49:381-9. CD. Psychol Med 1988;18:49-55.

7 OPCS. Classification of Occupation. London, HMSO, 1981.

8 Brown RG, MacCarthy B, Jahanshahi M, Marsden CD. The accuracy of self-reported disability in patients with parkinsonism. Arch Neurol 1989;46:955-9.

9 Rust J, Golombok S. The Golombok Rust Inventory of Sexual Satisfaction. Windsor: NFER-Nelson, 1986.

10 Rust J, Bennun I, Crowe M, Golombok S. The Golombok Rust Inventory of Marital State. Sexual and Marital Therapy 1988;1:55-60.

11 Beck AT, Beamesderfer A. Assessment of Depression: the depression inventory. In: Pichot P, ed. Psychological measurements in psychopharmacology, Vol 7. Paris: Kargel-
Basel, 1974.

12 Spielberger CD, Gorsuch RL, Lushene RE. Manual for the State-Trait Anxiety Inventory. Palo-Alto, California: Consulting Psychologists Press, 1970.

13 Felton BJ, Revenson TA. Coping with chronic illness: a study of illness controllability and the influence of coping strategies on psychological adjustment. J Consult Clin Pstrategies on psychologic 1984;2:343-53.

14 Robinson BC. Validation of a caregiver strain index. $J$ Gerontol 1983;38:344-8.

15 Beck AT. Depression. Philadelphia: University of Pennsylvania Press, 1970.

16 Frank EF, Anderson C, Rubinstein D. Frequency of sexual dysfunction in "normal" couples. N Engl J Med 1978;299:111-5.

17 Osborn M, Hawton K, Gath D. Sexual dysfunction among middle aged women in the community. Brit Med $J$ 1988;296:959-62.

18 Stewart WFR. Sex and the Physically Handicapped. Horsham: National Fund for Research in Crippling Disease,
1975 . 